\title{
Does the use of a big data variable improve monetary policy estimates? Evidence from Mexico
}

\author{
Luis Alberto Delgado-de-la-Garza • Gonzalo Adolfo Garza-Rodríguez • \\ Daniel Alejandro Jacques-Osuna • Alejandro Múgica-Lara • Carlos Alberto Carrasco*
}

Departamento de Economía, Universidad de Monterrey (UDEM, Mexico)

Received: 7 July 2020

Revised: 24 February 2021

Accepted: 5 April 2021

\begin{abstract}
We analyse the performance improvement on a monetary policy model of introducing nonconventional market attention (NCMA) indices generated using big data. To address this aim, we extracted top keywords by text mining Banco de Mexico's minutes. Then, we used Google search information according to the top keywords and related queries to generate NCMA indices. Finally, we introduce as covariates the NCMA indices into a bivariate probit model of monetary policy and contrast several specifications to examine the improvement in the model estimates. Our results show evidence of the statistical significance of the NCMA indices where the expanded model performed better than models only including conventional economic and financial variables.
\end{abstract}

Keywords: Monetary policy forecasting; Big data; Banco de Mexico; Market attention JEL Classification Codes: E47, E52, E58

\section{Introduction}

The increasing availability of data has led to a change in the estimation capacity of monetary policy. Economic agents are affected in different ways by monetary policy decisions. Thus, accurate estimates of monetary policy would potentially improve their decision-making process. There are several complications in monetary policy assessments, including uncertainty in the economic environment and soft-side considerations of policymakers. However, this has not stopped researchers from proposing and estimating predictive monetary policy models, ranging from the use of purely economic and financial variables as predictors, to incorporating communication and sentiment variables in more recent studies (Jansen and De Haan, 2009; Pereira and Valls-Pereira, 2018).

Estimation strategies have been improved by the growing capacity to collect and process massive amounts of information. The use of Google searches as predictors for economic variables

\footnotetext{
${ }^{*}$ Corresponding author. E-mail: carlos.carrasco@udem.edu.
}

Citation: Delgado-de-la-Garza, L. A., Garza-Rodríguez, G. A., Jacques-Osuna, D. A., Múgica-Lara, A., and Carrasco, C . A. (2021) Does the use of a big data variable improve monetary policy estimates? Evidence from Mexico, Economics and Business Letters, 10(4), 383-393.

DOI: 10.17811/ebl.10.4.2021.383-393 
is a clear example (Choi and Varian, 2009; Lucca and Trebbi, 2009; Silverstovs and Wochner, 2018; Durán-Bustamante, Hernandez-del-Valle and Ortiz, 2019). In this regard, if the public increases Google searches when there exists concern about achieving price stability, -for instance, when a deviation from the inflation target is expected- this information could be used as an input in a predictive monetary policy model. Under this premise, we propose the construction of a non-conventional market attention (NCMA) index that incorporates information from Google searches and related queries of key terms resulting from text mining Banxico's minutes. NCMA indices are included as covariates into a bivariate probit model and several specifications are contrasted to examine the improvement in the estimated model.

\section{Monetary policy modelling and the use of big data}

Central bank decisions on monetary policy have long been a subject of interest for researchers and policymakers (Taylor, 1993; Clarida et al, 1999). From a predictive perspective, many different econometric methods have been used to estimate monetary policy decisions, including traditional economic and financial variables (McMillan, 2009; Baghestani and Danila, 2014; Lanne and Nyberg, 2016). However, more recent papers have analysed the usefulness of incorporating variables reflecting the communication efforts of central banks into conventional predictive models for interest rates, such as the statements of high-level policymakers, press releases and speeches by monetary policy officials (Pereira and Valls-Pereira, 2018; Hayo and Neuenkirch, 2013; Jansen and De Haan, 2009).

Economic literature on monetary policy modelling for the case of Mexico is limited (TéllezLeón and Venegas, 2013; Cuevas-Camarillo, 2003) and relies on traditional financial and economic variables as predictors such as production, inflation, market interest rates and inflation expectations. However, with the exponential rise of technological resources in the last decade, there are new estimation strategies to be explored that can predict monetary policy decisions in a potentially more accurate manner - for instance, by including big data.

Big data can be defined as the large and diverse data generated from economic transactions and social media interactions (Armah, 2013). It has four main characteristics: volume; variety; velocity; and value. Big data has had significant results in fields such as meteorology, biology, physics, chemistry and astronomy (Schintler and Kulkarni, 2014).

However, the use of big data beyond these areas has been limited. Thus, including big data on economic policy analysis is relatively new. Papers including big data as part of their methodology are quite recent. For instance, Choi and Varian (2009) are two of the first authors who incorporate Google Trends on economic research. They analyse whether Google Trends helps improve the prediction of future unemployment levels measured through an initial unemployment claims proxy variable. They conclude that there exists a significant positive correlation between Google Trends searches for jobs- and welfare-related terms and unemployment. Silverstovs and Wochner (2018) test how reliable Google Trends behaviour is to reflect real economic conditions in Switzerland and conclude that search indicators are valuable complements for the guidance of economic policy.

For their part, Lucca and Trebbi (2009) are pioneers on the use of a search index to measure changes in monetary policy. Using statements released by the Federal Open Market Committee, they seek to measure the Federal Reserve's future interest rate decisions based on Google-specific word searches. As a result of this, they find that yields in long-term bonds respond better to changes in communication than yields in short-term bonds. More recently, Wohlfarth (2018) analyse monetary policy proposing a Monetary Policy Search Index based on daily Google Trends' data to examine volatility spillovers on US and European fixed income markets. Wohlfarth found that the impact of monetary policy provides evidence for an international channel of monetary transmission on capital and money markets. 
Economic literature using big data is even scarcer in the case of Mexico. Durán-Bustamante, Hernandez-del-Valle and Ortiz (2019) investigate the advantages of using Google Trends to predict MXN/USD exchange rate volatility in the short term. They concluded that Google Trends only partially explains the behaviour of volatility as it does not capture all financial decisions taken in the currency markets.

The massive and unprecedented amount of data allows the broadening of the monetary policy analysis possibilities. In this regard, our empirical proposal estimates a monetary policy model including a variable constructed using big data. We depart by assuming that the public increases Google searches when there exists concern about achieving price stability and, therefore, the frequency that people search key terms increases. If this assumption is accurate, Google Trends could be used as an input for estimating non-conventional market attention (NCMA) indices. Specifically, we analyse whether the performance of a predictive model for monetary policy tightening that uses conventional variables is improved by adding NCMA indices.

\section{Data and methodology}

For the empirical analysis, we follow previous literature on monetary policy forecasting (Téllez-León and Venegas, 2013; Jansen and De Haan, 2009; and Jung, 2018). We estimate a monetary policy predictive bivariate probit model. Using a probit model overcomes limitations of the linear probability model by transforming the regression using a cumulative normal distribution. This transformation produces probabilities of occurrence that lie between the $(0,1)$ interval.

The dependent variable is of binary nature, taking the value of 1 when Banxico raises the instrumental interest rate (tightening monetary policy) and 0 otherwise. The baseline model includes a set of conventional economic and financial variables commonly used in economic literature of monetary policy forecasting (Laopodis, 2006; Téllez-León and Venegas, 2013; Barro and Gordon, 1983; Svensson, 1997; Avdjiev and Zeng, 2014; Bjørnland and Halvorsen, 2014; Crespo-Cuaresma et al., 2016; Carrasco and Ferreiro, 2013; Jung, 2018). The baseline model includes as regressors (expected sign and abbreviation are show in parentheses): inflation $\left(+\right.$, Inf); inflation expectations (+, InfExp); output gap ${ }^{1}(+$, OutputGap); and MXN/USD exchange rate $(+$, ExchRat). In addition, as a robustness checking exercise, Models 2 to 4 expand baseline models by including two market expectation variables: 1-month interest rate differentials between the US and the Mexican federal government bonds (CETES) (+); and the slope of the Mexican yield curve (+) using CETES interest rates.

Data include monthly observations from February 2008 to December 2018. We incorporate one lag for all explanatory variables to address the potential problem of bidirectional causality and to forecast monetary policy movements with more recent available data. Conventional variables were retrieved from different sources: inflation and IGAE from INEGI; inflation expectations are the median of the Banxico's monthly survey to the private sector economic specialists; MXN/USD exchange rate, 1-month CETES interest rate and 1-year CETES interest rate from Banxico; 1-month US Treasury rate from the U.S. Department of the Treasury.

As stated above, we analyse the performance improvement on the baseline model of introducing non-conventional market attention (NCMA) indices generated using big data. NCMA indices capture the populations' interest in the current state of the economy.

To generate NCMA variables, we used Google Trends, which provides information on the behaviour of the total monthly searches of a specific term. Which keywords should be included in the Google Trends search? To answer this question, we follow Chague et al. (2015) and Lucca and Trebbi (2009) who revise the central banks' public statements for the most-used

\footnotetext{
${ }^{1}$ Output gap is obtained using the Hodrick-Prescott filter on IGAE, a global index of economic activity. IGAE is used as a monthly proxy for GDP.
} 
words. Therefore, we make a quantitative analysis of the content of the minutes of Banxico's meetings, focusing on the repetition of economic terms through a text mining process. We gather all the minutes available on the Banxico's public website and divided them into three categories: when instrumental interest was raised, lowered, or remained unchanged. Then, we analysed the frequency of the most-used terms (excluding stop words) across all three types of documents. The most-used frequent terms are similar independently if the instrumental rate was raised, lowered, or remained unchanged. Thus, we include in the Google search the most general used terms independently of the decision on the instrumental rate. We depart from the idea that when public is more concerned about the price stability -and a tightening of monetary policy is more likely-, the Google searches for the key terms increased.

More frequently used terms and top related queries were introduced in Google Trends and extracted as search indices. ${ }^{2}$ Search indices extracted from Google Trends were included as inputs in a principal component analysis (PCA; Abdi and Williams, 2010). The term NCMA indices refers to the first component of the PCA. NCMA indices are included as covariates in our Banxico's monetary policy model.

We follow nine different strategies to estimate NCMA indices (see Table 1). To calculate NCMA variables, we include the top $25 \%$, the top five and the top three most frequently used terms obtained from text-mining Banxico's minutes with (3 or 5) and without related queries. The nine methodologies are coded according to the number of frequent terms and related queries. The first part represents the number of Banxico terms, where Top25 includes the top 25\% of the most repeated terms, Top5 includes the top five most frequent terms, and Top3 includes the top three most frequent terms. On the other hand, the second part represents the number of related queries included, where 0 represents no related queries included, 3 represents the top three related queries included, and 5 represents the top five related queries. Before including the terms in the PCA, we remove repeated terms and terms that exhibited an overall different behaviour than most of the frequent words.

Table 1. Estimation strategy for NCMA index generated using Google Trends.

\begin{tabular}{cllll}
\hline \hline & \multicolumn{5}{c}{ Most frequent terms in Banxico's minutes } \\
\cline { 2 - 5 } Related & Top 25\% & Top 5 & Top 3 \\
\cline { 2 - 5 } Queries & $\mathbf{3}$ & Top25-0 (19 terms) & Top5-0 (5 terms) & Top3-0 (3 terms) \\
& $\mathbf{5}$ & Top25-3 (59 terms) & Top5-3 (18 terms) & Top3-3 (12 terms) \\
\hline \hline
\end{tabular}

Therefore, the regression analysis was divided in two groups of models. The first one -given by Eq. (1)- is the baseline model including only conventional economic and financial variables.

$$
\begin{gathered}
\text { IntRate }_{t}=\beta_{1}+\beta_{2} \operatorname{Inf}_{t-1}+\beta_{3} \operatorname{InfExp}_{t-1}+\beta_{4} \text { OutputGap }_{t-1}+\beta_{5} \text { ExchRat }_{t-1} \\
+u_{t}
\end{gathered}
$$

Finally, to test our research hypothesis, baseline model is expanded by including NCMA indices as stated in Eq. (2)

$$
\begin{gathered}
\text { IntRate }_{t}=\beta_{1}+\beta_{2} \text { Inf }_{t-1}+\beta_{3} \text { InfExp }_{t-1}+\beta_{4} \text { OutputGap }_{t-1}+\beta_{5} \text { ExchRat }_{t-1} \\
+\beta_{6} \text { NCMA }_{t-1}+u_{t}
\end{gathered}
$$

\footnotetext{
${ }^{2}$ Google Trend Index for a given term tends to be slightly different every time it is retrieved. This happens in both, the official page for Google Trends and using the gtrendsR package in R. Nevertheless, the correlation coefficient between both indices was higher than 0.9 and overall results do not change significantly.
} 


\section{Results}

Table 2 shows results ${ }^{3}$ for the baseline model (Model 1) and the expanded model including conventional market expectation variables (Models 2 to 4). Results show a significant and robust effect of output gap and exchange rate with the expected sign across the different specifications. Additionally, interest rate differential and the yield curve slope show consistent and significant results at $90 \%$ confidence.

In contrast, results for inflation and inflation expectations were not robust, as their coefficients' significance and sign depend on the specification. Inflation remained non-significant across all models and the sign of the coefficient varies across the specifications. Inflation expectations were only significant in Model 4 at $95 \%$ confidence level with an unexpected negative sign. Inflation expectations have remained within Banxico's inflation target range during the analysed period, even when observed inflation was higher than the target. This could be evidence of the credibility of Banxico's commitment to price stability.

Table 3 shows results of expanded models including NCMA indices. ${ }^{4}$ Models 5 to 13 correspond to NCMA indices Top25-0, Top25-3, Top25-5, Top5-0, Top5-3, Top5-5, Top3-0, Top33 and Top3-5, respectively, as described in Table 1. As in Table 2, results of Models 5 to 13 show a significant and robust effect of output gap and exchange rate with the expected sign. The robustness of these results is verified in all different specifications. Similarly, inflation is not significant but now the sign is that expected. Moreover, in most of the specifications, inflation expectations are significant at $90 \%$ confidence level. However, the sign is not the expected one.

Table 2. Baseline models (including only conventional financial and economic variables).

\begin{tabular}{|c|c|c|c|c|}
\hline \multicolumn{5}{|c|}{ Dependent variable: 1 when Banxico raises the instrumental interest rate and 0 otherwise. } \\
\hline Variable & Model 1 & Model 2 & Model 3 & Model 4 \\
\hline \multirow[t]{2}{*}{ Constant } & -2.91 & -0.02 & -1.70 & 1.39 \\
\hline & $(3.05)$ & $(3.59)$ & $(3.17)$ & (3.86) \\
\hline \multirow{2}{*}{ Lagged Inflation } & 17.18 & -15.56 & 29.29 & -4.27 \\
\hline & $(15.73)$ & $(23.40)$ & $(18.01)$ & $(25.17)$ \\
\hline \multirow{3}{*}{ Lagged inflation expectations } & & & & \\
\hline & -0.78 & -1.78 & -1.41 & $2.436 * *$ \\
\hline & $(0.87)$ & (1.11) & $(1.00)$ & (1.24) \\
\hline \multirow{2}{*}{ Lagged output gap } & $0.204 * * *$ & $0.183 * * *$ & $0.217 * * *$ & $0.193 * * *$ \\
\hline & $(0.07)$ & $(0.07)$ & $(0.07)$ & $(0.07)$ \\
\hline \multirow{2}{*}{ Lagged exchange rate } & $0.247 * * *$ & $0.226 * * *$ & $0.239 * * *$ & $0.215 * * *$ \\
\hline & $(0.06)$ & $(0.06)$ & $(0.06)$ & $(0.06)$ \\
\hline \multirow[t]{2}{*}{ Lagged US-Mex interest rate differentials } & -- & $0.547 *$ & -- & $0.553^{*}$ \\
\hline & & $(0.28)$ & & $\begin{array}{r}(0.29) \\
1754 *\end{array}$ \\
\hline Lagged yield curve slope & -- & -- & $\begin{array}{c}1.804^{*} \\
(1.06)\end{array}$ & $\begin{array}{r}1 . / 54 * \\
(1.05)\end{array}$ \\
\hline Observations & 130 & 130 & 130 & 130 \\
\hline Log Likehood & -36.40 & -34.54 & -34.84 & -33.07 \\
\hline Akaike Inf. Crit. & 82.80 & 81.08 & 81.68 & 80.15 \\
\hline \multirow[t]{2}{*}{ Residual deviance } & 72.796 & 69.083 & 69.676 & 66.146 \\
\hline & $(\mathrm{df}=125)$ & $(\mathrm{df}=124)$ & $(\mathrm{df}=124)$ & $(\mathrm{df}=123)$ \\
\hline
\end{tabular}

Note: $* \mathrm{p}<0.1 ; * * \mathrm{p}<0.05 ; * * * \mathrm{p}<0.01$.

\footnotetext{
${ }^{3}$ Information on the average marginal effects are available upon request. Marginal effects show the same significance and sign as the coefficients in the estimations.

${ }^{4}$ Due to potential collinearity concerns, specifications in Table 3 does not include market expectations variables (US-Mex interest rate differentials, and the slope of the Mexican yield curve). For instance, the results shown by the interest rate differential change drastically when adding NCMA indices, suggesting the existence of conflict between the two. Table $1 \mathrm{~A}$ show results including market expectations variables.
} 
Regarding the big data variable, the first result of interest is the statistical evidence of a correlation between NCMA indices and monetary policy decisions, with robustness and consistency that transcend methodologies. All different NCMA indices are significant with a consistently negative sign. In Models 5, 7 and 11 (Top25-0, Top25-5, Top3-0), the NCMA indices are significant at 99\% confidence level, while in Models 6, 8, 9, 10, 12 and 13 (Top25-3, Top50, Top5-3, Top5-5, Top3-3 and Top3-5), they are significant at 95\% confidence level. Please be aware that Augmented Dickey-Fuller and Phillips-Perron unit root tests do not reject the null hypothesis of a unit root for NCMA indices Top5-0, Top5-3, and Top5-5. Thus, Model 8-10 should be interpreted with caution.

Our results show that, overall, the inclusion of the non-conventional variable improves the performance of baseline models, regardless of the methodology employed to construct it. Based on the Akaike Information Criterion (AIC), models including NCMA indices consistently performed better than baseline models while maintaining robust results across models with high levels of significance on output gap and exchange rate. In addition, the expectation-prediction evaluation shows that augmented models overperform models only including conventional variables.

The non-conventional variable is also consistent in both the magnitude of the coefficient and the negative sign. The model that minimizes the AIC (model 11, Top3-0) includes the top three most frequently used terms without related queries. Related queries do not significantly alter the results obtained. In Model 11, the first component explains $86.2 \%$ of the variance. In general terms, models tend to perform better when fewer terms are included in the estimation of the NCMA indices. Our results show the relevance of including a non-conventional market attention variable as a covariate in a monetary policy forecasting model.

\section{Conclusions}

In this paper we estimate a monetary policy model including a variable constructed using big data. Specifically, we analysed whether the performance of a predictive model that uses conventional financial and economic variables is improved by adding a non-conventional market attention (NCMA) index.

Our results highlight the role of output gap and exchange rate for anticipating a monetary policy tightening in Mexico. Sign, magnitude and significance of output gap and exchange rate are robust across several specifications. More important for this research, the inclusion of NCMA indices improves the monetary policy modelling compared to the baseline model only including conventional variables. NCMA indices were statistically significant and their inclusion yielded a lower AIC than in baseline models, regardless of the methodology employed to construct it.

Our findings have relevant economic policy implications. The increasing capacity to collect and process massive amounts of data makes possible the generation of new variables and socioeconomic indicators which enhance the understanding of the economy and the economic policy decision-making. In this regard, central banks could provide information to economic agents using variables generated with big data. This would be relevant in two dimensions. On the one hand, as an internal indicator, improving monetary policy decision-making. On the other hand, as external indicator toward the public, as a part of their information and transparency policies.

The inclusion of big data in economic research still presents some limitations, for instance, the access cost to big data, the early-stage development of specific methodologies for this kind of information and data structure. We address these problems using Google Trends and PCA. However, future research should contemplate these difficulties to improve the use of big data in monetary policy modelling. 
Table 3. Expanded models with NCMA indices.

\begin{tabular}{|c|c|c|c|c|c|c|c|c|c|}
\hline \multicolumn{10}{|c|}{ Dependent variable: 1 when Banxico raises the instrumental interest rate and 0 otherwise. } \\
\hline Variable & Model 5 & Model 6 & Model 7 & Model 8 & Model 9 & Model 10 & Model 11 & Model 12 & Model 13 \\
\hline Constant & -5.70 & $-6.327^{*}$ & $-6.564 *$ & -4.85 & $-6.079 *$ & -5.34 & -5.88 & -5.91 & -5.96 \\
\hline & 3.68 & 3.78 & 3.81 & 3.42 & 3.65 & 3.48 & 3.69 & 3.66 & 3.66 \\
\hline Lagged Inflation & 8.03 & 8.28 & 8.70 & 11.53 & 9.43 & 11.14 & 4.51 & 8.62 & 8.98 \\
\hline & 17.57 & 17.53 & 17.53 & 16.94 & 17.39 & 16.92 & 18.36 & 17.60 & 17.49 \\
\hline Lagged inflation expec- & -1.74 & $-2.040^{*}$ & $-2.008 *$ & $-1.749 *$ & $-2.095^{*}$ & $-1.680^{*}$ & $-1.94^{\prime} *$ & $-1.906^{*}$ & $-1.872^{*}$ \\
\hline tations & 1.06 & 1.10 & 1.10 & 1.05 & 1.09 & 1.01 & 1.10 & 1.07 & 1.06 \\
\hline Lagged output gap & $0.179 * * *$ & $0.185^{* * *}$ & $0.186^{* * *}$ & $0.201 * * *$ & $0.202 * * *$ & $0.191 * * *$ & $0.196 * * *$ & $0.193 * * *$ & $0.192 * * *$ \\
\hline & 0.07 & 0.07 & 0.07 & 0.07 & 0.07 & 0.07 & 0.07 & 0.07 & 0.07 \\
\hline Lagged exchange rate & $0.412 * * *$ & $0.477 * * *$ & $0.487 * * *$ & $0.391 * * *$ & $0.459 * * *$ & $0.429 * * *$ & $0.450 * * *$ & $0.468 * * *$ & $0.474 * * *$ \\
\hline & 0.10 & 0.12 & 0.13 & 0.10 & 0.16 & 0.11 & 0.11 & 0.12 & 0.12 \\
\hline NCMA index Top25-0 & $\begin{array}{r}-0.022 * * * \\
0.01\end{array}$ & -- & -- & -- & -- & -- & -- & -- & -- \\
\hline NCMA index Top25-3 & -- & $\begin{array}{r}-0.016 * * \\
0.01\end{array}$ & -- & -- & -- & -- & -- & -- & -- \\
\hline NCMA index Top25-5 & -- & -- & $\begin{array}{r}-0.013 * * * \\
0.01\end{array}$ & -- & -- & -- & -- & -- & -- \\
\hline NCMA index Top5-0 & -- & -- & -- & $\begin{array}{r}-0.032 * * \\
0.02\end{array}$ & -- & -- & -- & -- & -- \\
\hline NCMA index Top5-3 & -- & -- & -- & -- & $\begin{array}{r}-0.025 * * \\
0.01\end{array}$ & -- & -- & -- & -- \\
\hline NCMA index Top5-5 & -- & -- & -- & -- & -- & $\begin{array}{r}-0.015^{* *} \\
0.01\end{array}$ & -- & -- & -- \\
\hline NCMA index Top3-0 & -- & -- & -- & -- & -- & -- & $\begin{array}{r}-0.054 * * * \\
0.02\end{array}$ & -- & -- \\
\hline NCMA index Top3-3 & -- & -- & -- & -- & -- & -- & -- & $\begin{array}{r}-0.026 * * \\
0.01\end{array}$ & -- \\
\hline NCMA index Top3-5 & -- & -- & -- & -- & -- & -- & -- & -- & $\begin{array}{r}-0.020 * * \\
0.01 \\
\end{array}$ \\
\hline Observations & 130 & 130 & 130 & 130 & 130 & 130 & 130 & 130 & 130 \\
\hline Log Likelihood & -32.58 & -32.49 & -32.53 & -34.39 & -33.276 & -34.123 & -32.33 & -33.214 & -33.321 \\
\hline Akaike Inf. Crit. & 77.17 & 76.98 & 77.06 & 80.79 & 78.552 & 80.247 & 76.667 & 78.427 & 78.642 \\
\hline Residual deviance & $\begin{array}{r}65.165 \\
(\mathrm{df}=124)\end{array}$ & $\begin{array}{r}64.976 \\
(\mathrm{df}=124)\end{array}$ & $\begin{array}{r}65.057 \\
(\mathrm{df}=124)\end{array}$ & $\begin{array}{r}68.787 \\
(\mathrm{df}=124)\end{array}$ & $\begin{array}{r}66.552 \\
(\mathrm{df}=124)\end{array}$ & $\begin{array}{r}68.247 \\
(\mathrm{df}=124)\end{array}$ & $\begin{array}{r}64.667 \\
(\mathrm{df}=124)\end{array}$ & $\begin{array}{r}66.427 \\
(\mathrm{df}=124)\end{array}$ & $\begin{array}{r}66.642 \\
(\mathrm{df}=124)\end{array}$ \\
\hline $\begin{array}{l}\text { Variance explained by } \\
\text { first component }\end{array}$ & $56.7 \%$ & $51.1 \%$ & $50.0 \%$ & $73.3 \%$ & $62.6 \%$ & $65.7 \%$ & $86.2 \%$ & $77.2 \%$ & $74.6 \%$ \\
\hline
\end{tabular}

Note: $* p<0.1 ; * * p<0.05 ; * * * p<0.01$ 


\section{References}

Abdi, H. and Williams, L.J. (2010) Principal component analysis, Wiley Interdisciplinary Reviews Computational Statistics, 2(4), 433-459.

Armah, N. (2013) Big Data Analysis: The Next Frontier, Bank of Canada Review, Summer, 32-39.

Avdjiev, S., and Zeng, Z. (2014) Credit Growth, Monetary Policy, and Economic Activity in a Three-Regime TVAR Model, Applied Economics, 46(24), 2936-2951.

Baghestani, H., and Danila, L. (2014) Interest rate and exchange rate forecasting in the Czech Republic: Do analysts know better than a random walk? Finance a Uver - Czech Journal of Economics and Finance, 64(4), 282-295.

Barro, R.J. and Gordon, D.B. (1983) Rules, discretion and reputation in a model of monetary policy, Journal of Monetary Economics, 12(1), 101-121.

Bjørnland, H., and Halvorsen, J. (2014) How does Monetary Policy Respond to Exchange Rate Movements? New International Evidence, Oxford Bulletin of Economics and Statistics, 76(2), 208-232.

Carrasco, C. A. and Ferreiro, J. (2013) Inflation Targeting and Inflation Expectations in Mexico, Applied Economics, 45(23), pp. 3295-3304.

Chague, F., De-Losso, R., Giovannetti, B., and Manoel, P. (2015) Central Bank Communication Affects the Term-Structure of Interest Rates, Revista Brasileira de Economia, 69(2), 147162.

Choi, H., and Varian, H. (2009) Predicting Initial Claims for Unemployment Benefits, Google Inc, 1-5 < https://research.google.com/archive/papers/initialclaimsUS.pdf >.

Clarida, R., Galí, J., and Gertler, M. (1999) The science of monetary policy: A new Keynesian perspective, Journal of Economic Literature, 37(4), 1661-1707.

Crespo-Cuaresma, J., Doppelhofer, G., Feldkircher, M., and Huber, F. (2016) US monetary policy in a globalized world, CESifo Working Paper Series 5826, CESifo.

Cuevas-Camarillo, A. (2003) Los determinantes de la decisión de aumentar la restricción monetaria en México, Mimeo. < http://200.74.197.135/Upload/Eventos/VIIIReunion/mexico_cuevas.pdf >

Durán-Bustamante, M., Hernandez-del Valle, A., and Ortiz-Ramírez, A. (2019) The Google Trends Effect on the behavior of the exchange rate Mexican peso - US dollar, Contaduría y Administración, 64(2), 1-14.

Hayo, B., and Neuenkirch, M. (2013) Do Federal Reserve presidents communicate with a regional bias?, Journal of Macroeconomics, 35, 62-72.

Jansen, D.-J., and De Haan, J. (2009) Has ECB Communication Been Helpful in Predicting Interest Rate Decisions? An Evaluation of the Early Years of the Economic and Monetary Union, Applied Economics, 41(16), 1995-2003.

Jung, A. (2018) Have money and credit data releases helped markets to predict the interest rate decisions of the European Central Bank?, Scottish Journal of Political Economy, 65(1), 3967.

Lanne, M., and Nyberg, H. (2016) Generalized Forecast Error Variance Decomposition for Linear and Nonlinear Multivariate Models, Oxford Bulletin of Economics and Statistics, 78(4), 595-603.

Laopodis, N. (2006) Dynamic Interactions among the Stock Market, Federal Funds Rate, Inflation, and Economic Activity, The Financial Review, 41(4), 513-545.

Lucca, D.O., and Trebbi, F. (2009) Measuring Central Bank Communication: An Automated Approach with Application to FOMC Statements, NBER Working Paper No. 15367.

McMillan, D.G. (2009) Non-linear interest rate dynamics and forecasting: Evidence for US and Australian interest rates, International Journal of Finance and Economics, 14(2), 139-155. 
Pereira, L.F. and Valls-Pereira, Pedro L. (2018) Effects of official and unofficial central bank communication on the Brazilian interest rate curve, Textos para discussão 470, FGV EESP - Escola de Economia de São Paulo, Fundação Getulio Vargas, Brazil.

Schintler, L.A. and Kulkarni, R. (2014) Big Data for Policy Analysis: The Good, The Bad, and The Ugly, Review of Policy Research, 31(4), 343-348.

Silverstovs, B., and Wochner, D. S. (2018) Google Trends and Reality: Do the Proportions Match? Appraising the Informational Value of Online Search Behavior: Evidence from Swiss Tourism Regions, Journal of Economic Behavior \& Organization, 145, 1-23.

Svensson, L.E.O. (1997) Inflation forecast targeting: Implementing and monitoring inflation targets, European Economic Review, 41(6), 1111-1146

Taylor, J. B. (1993) Discretion versus policy rules in practice, Carnegie-Rochester Conference Series on Public Policy, 39, 195-214.

Téllez-León, I. E., and Venegas, F. (2013) Principales determinantes en las decisiones de política monetaria de México: Un análisis econométrico, Estudios Económicos, 28(1), 79-108.

Wohlfarth, P. (2018) Measuring the impact of monetary policy attention on global asset volatility using search data, Economics Letters, 173, 15-18. 
Appendix A. Baseline model plus market expectations and NCMA indices.

Table 1A. Baseline model plus market expectations and NCMA indices.

\begin{tabular}{|c|c|c|c|c|c|c|c|c|c|}
\hline \multicolumn{10}{|c|}{ Dependent variable: 1 when Banxico raises the instrumental interest rate and 0 otherwise. } \\
\hline Variable & Model 14 & Model 15 & Model 16 & Model 17 & Model 18 & Model 19 & Model 20 & Model 21 & Model 22 \\
\hline \multirow[t]{2}{*}{ Constant } & -5.03 & -5.09 & -5.25 & -1.17 & -3.61 & -2.09 & -5.00 & -3.97 & -3.70 \\
\hline & 5.13 & 5.03 & 5.08 & 4.77 & 4.79 & 4.86 & 4.85 & 4.99 & 4.94 \\
\hline \multirow[t]{2}{*}{ Lagged Inflation } & 25.39 & 21.91 & 21.77 & 6.84 & 13.23 & 10.02 & 19.35 & 16.93 & 14.99 \\
\hline & 29.86 & 28.69 & 28.52 & 27.88 & 27.00 & 28.08 & 27.46 & 28.17 & 27.86 \\
\hline \multirow[t]{2}{*}{ Lagged inflation expectations } & $-2.357 *$ & $-2.764 * *$ & $-2.760 * *$ & $-2.564 * *$ & $-2.781 * *$ & $-2.524 * *$ & $-2.51 * *$ & $-2.625 * *$ & $-2.618 * *$ \\
\hline & 1.24 & 1.28 & 1.28 & 1.24 & 1.26 & 1.22 & 1.26 & 1.24 & 1.24 \\
\hline \multicolumn{10}{|l|}{ Lagged output gap } \\
\hline & $0.191 * * *$ & $0.197 * * *$ & $0.198 * * *$ & $0.198 * * *$ & $0.205 * * *$ & $0.193 * * *$ & $0.209 * * *$ & $0.202 * * *$ & $0.199 * * *$ \\
\hline & 0.07 & 0.07 & 0.07 & 0.07 & 0.08 & 0.07 & 0.08 & 0.08 & 0.07 \\
\hline \multirow[t]{2}{*}{ Lagged exchange rate } & $0.426 * * *$ & $0.482 * * *$ & $0.492 * * *$ & $0.314 * *$ & $0.440 * * *$ & $0.362 * *$ & $0.455 * * *$ & $0.445^{* * *}$ & $0.440 * * *$ \\
\hline & 0.14 & 0.17 & 0.17 & 0.14 & 0.17 & 0.15 & 0.15 & 0.17 & 0.17 \\
\hline Lagged US-Mex interest rate & -0.10 & -0.03 & -0.01 & 0.30 & 0.14 & 0.24 & -0.07 & 0.06 & 0.11 \\
\hline differentials & 0.43 & 0.39 & 0.38 & 0.40 & 0.36 & 0.39 & 0.39 & 0.39 & 0.38 \\
\hline \multirow[t]{2}{*}{ Lagged yield curve slope } & 1.61 & 1.66 & 1.68 & 1.68 & 1.60 & 1.71 & 1.55 & 1.64 & 1.65 \\
\hline & 1.08 & 1.08 & 1.08 & 1.05 & 1.05 & 1.05 & 1.07 & 1.06 & 1.06 \\
\hline NCMA index Top25-0 & $\begin{array}{r}-0.025^{*} \\
0.01\end{array}$ & -- & -- & -- & -- & -- & -- & -- & -- \\
\hline NCMA index Top25-3 & -- & $\begin{array}{r}-0.16^{*} \\
0.01\end{array}$ & -- & -- & -- & -- & -- & -- & -- \\
\hline NCMA index Top25-5 & -- & -- & $\begin{array}{r}-0.014 * \\
0.01\end{array}$ & -- & -- & -- & -- & -- & -- \\
\hline NCMA index Top5-0 & -- & -- & -- & $\begin{array}{r}-0.02 \\
0.02\end{array}$ & -- & -- & -- & -- & -- \\
\hline NCMA index Top5-3 & -- & -- & -- & -- & $\begin{array}{r}-0.02 \\
0.01\end{array}$ & -- & -- & -- & -- \\
\hline NCMA index Top5-5 & -- & -- & -- & -- & -- & $\begin{array}{r}-0.01 \\
0.01\end{array}$ & -- & -- & -- \\
\hline \multirow[t]{2}{*}{ NCMA index Top3-0 } & & & & & & & - & & \\
\hline & -- & -- & -- & -- & -- & -- & $\begin{array}{r}0.056 * * \\
0.03\end{array}$ & -- & -- \\
\hline NCMA index Top3-3 & -- & -- & -- & -- & -- & -- & -- & $\begin{array}{l}0.02 \\
0.02\end{array}$ & -- \\
\hline NCMA index Top3-5 & -- & -- & -- & -- & -- & -- & -- & -- & $\begin{array}{r}-0.02 \\
0.01 \\
\end{array}$ \\
\hline
\end{tabular}




\begin{tabular}{lrrrrrrrrr}
\hline Observations & 130 & 130 & 130 & 130 & 130 & 130 & 130 & 130 & 130 \\
Log Likelihood & -31.37 & -31.24 & -31.25 & -32.76 & -32.005 & -32.548 & -31.206 & -31.933 & -32.01 \\
Akaike Inf. Crit. & 78.74 & 78.49 & 78.50 & 81.52 & 80.01 & 81.097 & 78.413 & 79.865 & 80.02 \\
Residual deviance & 62.737 & 62.486 & 62.501 & 65.515 & 64.010 & 65.097 & 62.413 & 63.865 & 64.020 \\
& $(\mathrm{df}=122)$ & $(\mathrm{df}=122)$ & $(\mathrm{df}=122)$ & $(\mathrm{df}=122)$ & $(\mathrm{df}=122)$ & $(\mathrm{df}=122)$ & $(\mathrm{df}=122)$ & $(\mathrm{df}=122)$ & $(\mathrm{df}=122)$ \\
Variance explained by first component & $56.7 \%$ & $51.1 \%$ & $50.0 \%$ & $73.3 \%$ & $62.6 \%$ & $65.7 \%$ & $86.2 \%$ & $77.2 \%$ & $74.6 \%$ \\
\hline \hline
\end{tabular}

Note: $* \mathrm{p}<0.1 ; * * \mathrm{p}<0.05 ; * * * \mathrm{p}<0.01$. 